\title{
AN INVESTIGATION INTO FACTORS INFLUENCING CONSTRUCTION COSTS BASED ON J APANESE, UK AND US CONTRACTOR PRACTICE
}

\author{
Hong Xiao and David Proverbs \\ University of Wolverhampton
}

\section{INTRODUCTION}

Construction cost is known to be the top priority for construction clients (Davenport, 1997) because it determines the return on their investments. It is also a major concern to contractors as construction cost relates closely to their competitiveness and profitability. While affected by many internal and external factors, construction cost is considered a reliable and measurable indicator of contractor performance (Ahmed and Kangari, 1995; Tam and Harris, 1996). Through careful cost prediction and planning before the commencement of construction, and strict cost control and management during construction, contractors can realise their aspirations in this regard. Contractors may also reduce construction cost through technological innovation and improvements in productivity and management (CIDA, 1993). Improved cost performance benefits both clients and contractors, since this can lead to more competitive pricing for clients (Akintoye, 1995).

In the past two decades research on cost modelling has mainly been concerned with predicting and estimating the cost of construction projects at different phases. The cost model developed by Singh (1990) was used for cost estimation of reinforced concrete beam and slab structural systems in high-rise commercial buildings. Elhag and Boussabaine (1998) developed artificial neural network (ANN) models to predict tender price of education building projects. Adeli and Wu (1998) formulated a regularization neural network model to estimate the cost of construction projects. The parametric cost-estimating model developed by Hegazy and Ayed (1998) allowed users to reoptimise to their particular environment and predict budget costs of highway projects. Chau (1999) used the plan shape index to forecast building_construction cost during the early design stage. However, there has also been much effort directed towards identifying those factors found to influence project costs. For example, Ireland (1985) developed a model for high-rise commercial building projects to investigate the effects of managerial actions on cost reduction. The cost model from Dissanayaka and $\mathrm{Ku}$ maraswamy (1999) was created to compare the impact of procurement and nonprocurement variables on time and cost performance in building projects in Hong Kong.

The aim of this research is to compare and evaluate contractor performance internationally and to develop best performance models for contractors. This paper focuses on modelling cost performance. Here, a multiple regression model for construction cost is developed based on the construction practices found in the worlds' leading construction industries, namely J apan, the UK and the US, to identify the factors paramount to the construction cost of high-rise building projects. After briefly introducing the research methodology used, this paper presents the development of the model, followed by a discussion of the measures found to improve cost performance.

\section{METHODOLOGY}

As used by Proverbs (1998) and by OECD/Eurostat (Edkins and Winch, 1999; Vermande and Van Mulligen, 1999), this research uses an appropriate hypothetical project (a six-storey concrete framed office building considered common to the three countries) as the basis for a semistructured questionnaire survey for accruing the performance data. A broad, but carefully worded description of the project, including its location, gross floor area, height, and some basic technological characteristics is provided. A certain degree of flexibility, such as whether the concrete elements are pre-cast or in situ, facilitates the inclusion of some national vernacular characteristics into the design. Respondents (project managers of general contractors) are invited to answer questions related to the construction of the hypothetical project. Relative figures in the form of percentages and ratios are used as much as possible to maintain the comparability of data and to 
remove the need to identify matching or concurrent cases. This balances the requirements of the comparability and representativeness of data. Details of the hypothetical project and the questionnaire can be found in Xiao et al . (2000 and 2002).

In the questionnaire, respondents were asked to estimate the construction cost, assuming that they were the general contractor for the hypothetical project. Other information relevant to contractors' management and production practices, such as the average number of design variations encountered during construction, the frequency of meetings with subcontractors and project teams, and preferred construction methods, was also sought.

A survey was conducted simultaneously in J apan, the UK and the US. In J apan, translated versions of the questionnaires were distributed to contractors of the Building Contractors Society (BCS). General contractors in the US were contacted by means of a large contracting body, The Associated General Contractors of America (AGC). In the UK, companies listed in the Kompass Directory (Reed Business Information, 1999) and members of the $\mathrm{CIOB}$ (Chartered Institute of Building, 2000) were targeted in the survey. Detailed information about the distribution and response to the survey is shown in Table 1 . The relatively low response rate was not unexpected, considering the complexity and volume of the questionnaire. This, however, should not invalidate the outcome of the survey. Rather, it does imply that the questionnaire had been taken seriously and the responses received were both valid and reliable.

A cost model was subsequently developed to identify the relationships between construction cost (i.e., dependent variables) and contractors' preferred practices and methods (i.e., independent variables) in the building process. The aim of the model was to facilitate investigation as to what factors are important for achieving outstanding cost performance. The model can also assist in determining the importance of these factors to contractor cost performance.

Here, data used for modelling was based on an identical hypothetical construction project to minimise disturbance from the differences in project characteristics. Factors considered included both technical (such as construction methods and communication tools) and managerial (such as quality management and procurement methods) aspects. Findings from the research can demonstrate how contractors from these three countries (and possibly others) can improve their cost performance on buildings of the type considered.

\section{MULTTPLE REGRESSION ANALYSIS}

Multiple regression analysis is by far the most widely used multivariate technique used to analyse the relationship between a single dependent variable and several independent variables (Hair, J r. et al., 1995). It is usually used to predict a single dependent value through independent variables whose values are known. In addition to its predictive power, multiple regression analysis can also be used objectively to help explain the degree and character of the relationship between dependent and independent variables (Hair, J r. et al., 1995; J ohnson and Wichern, 1998). The independent variables, in addition to their collective prediction of the dependent variable, may also be considered for their individual contribution to the variate and its predictions. Interpretation of the variate may rely on any of three perspectives: the importance of the independent variables, the types of relationships found, or the interrelationships among the independent variables.

Table 1: Questionnaire survey

\begin{tabular}{|l|l|l|l|l|l|l|l|}
\hline & Distributed & \multicolumn{2}{l}{ Received } & \multicolumn{2}{l|}{$\begin{array}{l}\text { Held back for } \\
\text { validation }\end{array}$} & \multicolumn{2}{l|}{ Used in analyses } \\
\cline { 2 - 9 } & No. & No. & $\%$ & No. & $\%$ & No. & $\%$ \\
\hline J apan & 129 & 26 & 20.2 & 4 & 15.4 & 22 & 84.6 \\
\hline UK & 417 & 34 & 8.2 & 2 & 5.9 & 32 & 94.1 \\
\hline US & 113 & 38 & 33.6 & 6 & 15.8 & 32 & 84.2 \\
\hline Total & 659 & 98 & 14.9 & 12 & 12.2 & 86 & 87.8 \\
\hline
\end{tabular}


In this research, the explanation function of multiple regression analysis was utilised. As the dependent variable is the unit price for a hypothetical project, it would be of little practical meaning to use the model to predict the unit price of the hypothetical project in other circumstances. But through multiple regression analysis, the factors influencing contractor performance can be identified, the relationships between dependent and independent variables can be established, and the relative importance of each independent variable can be determined. With such, contractors can identify areas in need of improvement.

As multiple regression analysis is suitable only for modelling with metric variables, nominal variables need to be transformed by means of dummy variables. For questions with only 'Yes' and 'No' answers (e.g., whether the component is precast), the dummy variable can be defined as: $X=1$ for 'Yes', and $\mathrm{X}=\mathrm{O}$ for 'No'. For questions with more than two optional choices (e.g., 'Often', 'Occasionally', and 'None' for the use of different procurement methods), in order to make the analysis simpler, the answers are merged into two categories ('Often or Occasionally' and 'None') so that only one dummy variable is needed for each such variable.

The analysis was conducted with the aid of the Statistical Package for Social Sciences (SPSS 10). Only those independent variables which were significantly related to the unit price were incorporated into the modelling process. The Pearson correlation $(r)$ test is the most commonly used correlation coefficient that measures the strength of a linear association and was thus selected. The significance level was 0.05 (2-tailed). Multicollinearity among independent variables was assessed by means of the tolerance value with those less than 0.1 being omitted from the multiple regression analysis. As the aim of this research is to derive best practice among contractors internationally, their nationalities were not discriminated. That is, measurement of association and the modelling procedure were performed on the aggregated response.

\section{RESULTS}

To investigate what factors influence the construction cost of building projects, multiple regression analysis was applied to the dependent variable of construction cost in terms of unit price. Unit price was chosen because it was considered suitable for the assessment of contractor cost performance (Ireland, 1985; Naoum and Mustapha, 1995). Given that the exchange rates do not usually reflect the relative purchasing powers of currencies and constantly fluctuate (Kravis, 1984), the unit prices were adjusted by purchasing power parities (PPPs) (Xiao and Proverbs, 2002). Purchasing power parities (PPPs) are key statistical tools for international comparisons. They represent the rates of currency conversion that eliminate differences in price levels between countries. PPPs are a geometric average of price relatives of various products and services in a national economy including consumer goods and services, government services, equipment goods and construction projects. When prices of a product or service in different countries converted by PPPs are compared, they are all being valued at a common set of prices and they are not affected by the relative prices of tradable goods and by factors such as interest rates, financial flows, etc. (OECD, 2001).

Pearson correlation $(r)$ tests identified ten independent variables significantly related to unit price (refer to Table 2).

A stepwise multiple regression procedure was applied. Under the selection criteria (to enter, $F<=0.050$; to move, $F>=0.100$ ), four independent variables were selected, namely the percentage of overhead in unit price, the prefabrication of inner walls, the amount of design variation in construction, and the prefabrication of columns. The resulting $R^{2}$ was 0.408 , signifying that $41 \%$ of the total variation in the unit price could be explained by these four independent variables. The final regression model can be presented as:

$Y$ (Unit price in PPPs $)=523.417+20.636$ (OVERHEAD) + 267.891 (INNERWAI) + 1.114 (DVARIATI) +94.406 (COLUMNS1)

Here, OVERHEAD represents the percentage of overhead in unit price, DVARIATI represents the amount of design variations in construction, and INNERWAI and COLUMNS1 are dummy variables which equal one if the inner walls and columns are prefabricated and zero if otherwise.

The six variables eliminated in the regression were (i) the percentage of materials in unit price, (ii) the percentage of plant in unit 
price, (iii) the number of working days per week, (iv) whether the contractors possessed Quality Assurance certificates, (v) the use of management contracting procurement, and (vi) the use of design and management procurement.

The regression analysis results are summarised in Table 3.

The bell shaped and symmetrical histogram of standardized residuals for unit price in PPPs (refer to Figure 1) and the normal probability (P-P) plot for unit price in PPPs (refer to Figure 2 ) with points closely clustered to the diagonal line demonstrate that the model does not violate the assumption of normality. The random pattern of the data points in the plot of studentised residuals versus predicted values for unit price in PPPs (refer to Figure 3 ) indicates that the assumption of constant variance is not violated (Hair, J r. et al. 1995; Norusis, 1995). As the data were collected simultaneously from different contractors in different countries, it can be assumed that all the observations are independent, and the Durbin-Watson test (1.672) also confirmed this (Norusis, 1995).

Table 2: Matrix of correlation for unit price in PPPs

\begin{tabular}{|l|l|l|l|l|l|l|l|l|l|l|l|}
\hline & 1 & 2 & 3 & 4 & 5 & 6 & 7 & 8 & 9 & 10 & 11 \\
\hline 1 PPPS & 1.000 & & & & & & & & & & \\
\hline 2 MATERIAL & $-.236^{\mathrm{a}}$ & 1.000 & & & & & & & & & \\
\hline 3 PLANT & $.223^{\mathrm{a}}$ & $-.476^{\mathrm{b}}$ & 1.000 & & & & & & & & \\
\hline 4 OVERHEAD & $.397^{\mathrm{b}}$ & $-.251^{\mathrm{a}}$ & $.342^{\mathrm{b}}$ & 1.000 & & & & & & & \\
\hline 5 DVARIATI & $.298^{\mathrm{b}}$ & -.043 & -.112 & -.030 & 1.000 & & & & & & \\
\hline 6 WDAYS & $.257^{\mathrm{a}}$ & -.163 & .117 & $.220^{\mathrm{a}}$ & .057 & 1.000 & & & & & \\
\hline 7 CERTIFI2 & $.300^{\mathrm{b}}$ & .043 & $.267^{\mathrm{a}}$ & $.239^{\mathrm{a}}$ & .046 & $.407^{\mathrm{b}}$ & 1.000 & & & & \\
\hline 8 COLUMNS1 & $.252^{\mathrm{a}}$ & .120 & -.017 & .111 & .033 & .023 & -.089 & 1.000 & & & \\
\hline 9 INNERWA1 & $.371^{\mathrm{b}}$ & -.142 & $.487^{\mathrm{b}}$ & .130 & -.098 & $.249^{\mathrm{a}}$ & $.246^{\mathrm{a}}$ & .085 & 1.000 & & \\
\hline 10 MANACON1 & $.246^{\mathrm{a}}$ & -.047 & .179 & .002 & .123 & .151 & $.470^{\mathrm{b}}$ & .060 & .105 & 1.000 & \\
\hline 11 DESIMAN1 & $.212^{\mathrm{a}}$ & .054 & .070 & -.055 & .027 & .173 & $.368^{\mathrm{b}}$ & .026 & .159 & $.612^{\mathrm{a}}$ & 1.000 \\
\hline
\end{tabular}

a Correlation is significant at the 0.05 level (2-tailed).

b Correlation is significant at the 0.01 level (2-tailed).

Table 3: Regression analysis results of unit price in PPPs

\begin{tabular}{|c|c|c|c|c|c|c|c|}
\hline Multiple $R$ & & 0.639 & & ard error & 205.9904 & & \\
\hline$R^{2}$ & & 0.408 & & ed $R^{2}$ & 0.379 & & \\
\hline Durbin-Watson & & 1.672 & & & & & \\
\hline Analysis of varia & ince & DF & & f squares & Mean square & & \\
\hline Regression & & 4 & & 72.7 & 592418.177 & & \\
\hline Residual & & 81 & & 96.3 & 42432.053 & & \\
\hline$F=13.962$, Sig. $F$ & $F=0.000$ & & & & & & \\
\hline $\begin{array}{l}\text { Variables in the } \\
\text { equation }\end{array}$ & & $\mathrm{SE} B$ & Beta & $t$ & Sig. & Tolerance & MIF \\
\hline (Constant) & 523.417 & 51.080 & & 10.247 & 0.000 & & \\
\hline OVERHEAD & 20.636 & 5.207 & 0.344 & 3.963 & 0.000 & 0.972 & 1.028 \\
\hline INNERWA1 & 267.891 & 67.571 & 0.344 & 3.965 & 0.000 & 0.969 & 1.032 \\
\hline DVARIATI & 1.114 & 0.285 & 0.336 & 3.913 & 0.000 & 0.988 & 1.012 \\
\hline COLUMNS1 & 94.406 & 47.062 & 0.173 & 2.006 & 0.048 & 0.981 & 1.020 \\
\hline
\end{tabular}


Figure 1: Histogram of standardized residuals for unit price in PPPs

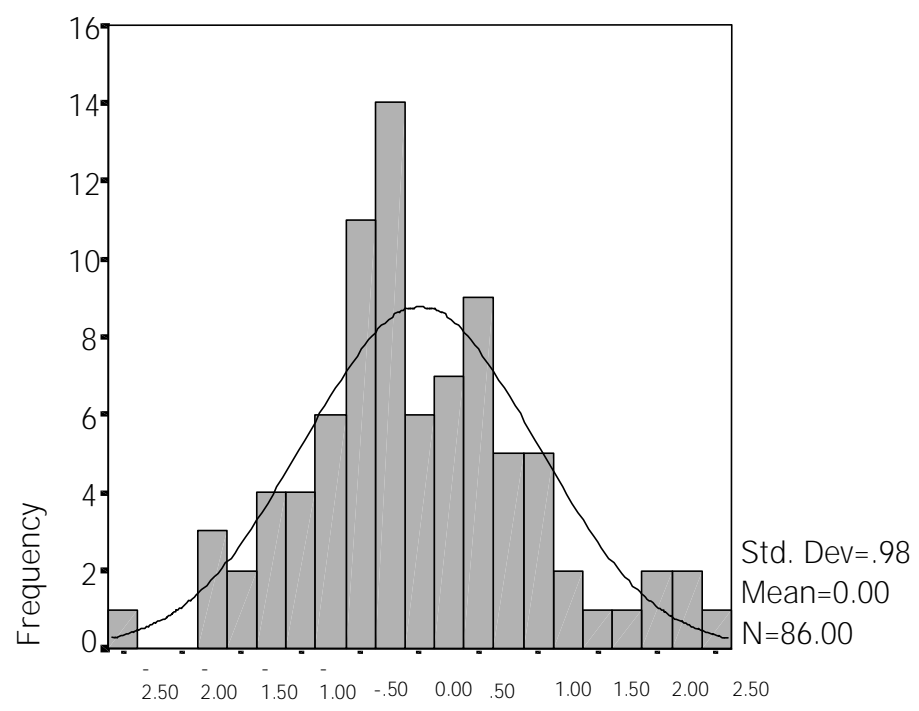

Regression Standardized

Figure 2: Normal probability (P-P) plot for unit price in PPPs

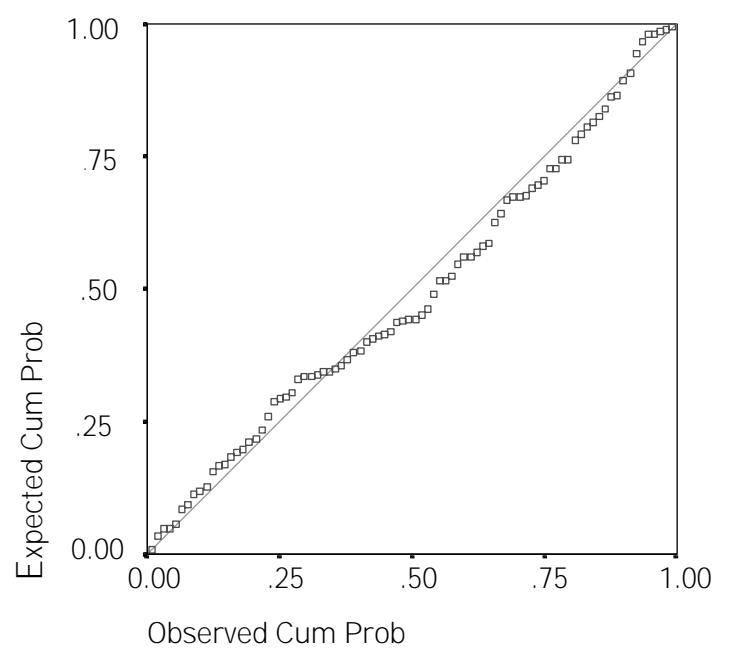

Figure 3: Studentized residuals versus predicted values for unit price in PPPs

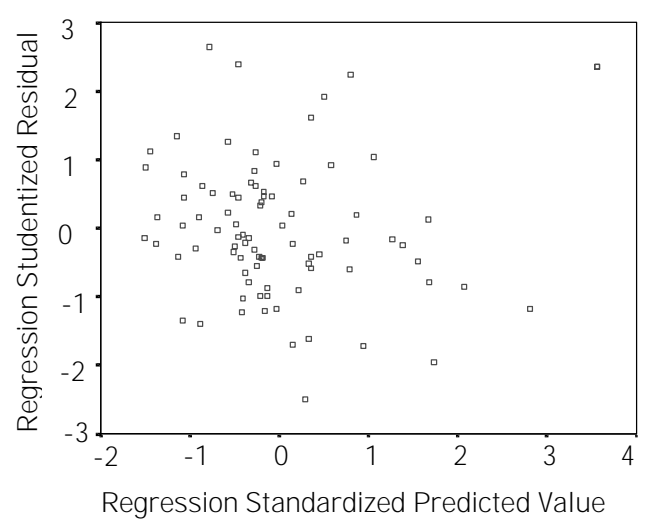


It is acknowledged that the resulting adjusted $R^{2}$ of the model is just moderate. However, it is unrealistic to assume that the complex nature of any economic relationships can be described accurately by a simple linear form (Newbold and Bos, 1990). For example, when Ball et al. (2000) used firm and industry characteristics to predict firm profitability, the adjusted $R^{2} s$ of regression were as low as 0.27 and 0.18 . Considering the international feature of this research, and the influence of differences in culture and values, the results of the modelling were deemed reasonable.

\section{DISCUSSION}

Multiple regression analysis revealed that overheads in the unit price and the use of prefabricated inner walls had the most significant impact on unit price with a beta coefficient of 0.344 , followed closely by design variations (0.336). The beta coefficient for prefabricated columns was 0.173 . These results provide guidance to contractors on how to reduce the cost of their building projects.

\section{Overheads in unit price}

The results of multiple regression analysis showed that the unit price of building projects (converted by PPPs) increased with the percentage of overheads. Overheads are the costs associated with the off-site expense of managing a company or facilitating the construction project, and include the costs of maintaining a head office, workshop and offsite storage compound for plant and materials (Ashworth, 1996; Brook, 1998). Overheads are recovered from projects undertaken by contractors in terms of percentage of turnover and may vary from project to project under different market situations. There are not many differences in direct cost (labour, plant, materials and subcontractors) estimating methods between contractors nowadays because they normally have access to the same labour supply, use the same type of equipment and obtain supplies and materials from the same sources (Tah et al., 1994). To make sufficient profit while maintaining a competitive position in the market, contractors need to reduce overheads in order to keep construction costs to an absolute minimum. Contractors should improve the efficiency of their management teams and effectiveness of their management systems, and concentrate on activities that can improve productivity. For example, the just-in-time (J IT) system, which means having the right items of the right quality and quantity in the right place and at the right time, can be implemented in construction projects to reduce overheads by eliminating non-valueadded activities, minimising inventory levels and improving productivity (Akintoye, 1995; Low and Mok, 1999).

\section{Use of prefabrication}

From this analysis, higher levels of prefabrication (specifically for inner walls and columns) will increase the cost of this type of building project (a six-storey concrete framed office building). This concurs with Arditi et al. (2000) who found that almost half of the contractors investigated claimed not to achieve cost savings by using prefabrication. Prefabrication removes the work from the site to the more controlled environment of the factory so that components and assemblies are manufactured off site or by the construction of temporary workshops or production units such as concrete precasting plant. Prefabricated components have been mainly used in industrialised residential buildings and large mass production is needed to achieve the proclaimed economic benefits (Ishai, 1989). However, delays in production can affect erection schedules and a lack of communication at the design stage can have negative effects on any cost saving. Fluctuations in the market make the production of prefabricated components unstable, and the increased cost in the production process has to be passed down the chain to contractors and clients. Furthermore, prefabricated concrete components are normally large, bulky and heavy and require the use of expensive cranes for hoisting, and the long delivery vehicles often pose problems to the traffic flow on site (Low and Choong, 2001). Prefabrication also demands higher costs in terms of transportation and factory overheads (d'Arcy, 1995). Greater co-ordination between clients, designers, manufacturers and contractors is needed before prefabrication can fully demonstrate its potential. Contractors need to carefully consider the use of prefabrication and plan this effectively into the production process if the desired results are to be achieved. 


\section{Design variations in construction}

The model indicated that design variations during construction increase the unit price of building projects, which is consistent with the findings of Ireland (1985). Variations were defined by Wallace (1995) as works which are not expressly or impliedly included in the original contract and therefore are not included in the contract price, whether they represent a change or alteration of the original work or simply an addition to or omission from it. Nearly all construction projects witness a number of design variations because of various problems such as the thoroughness of the predesign site investigation, the completeness of working drawings available at the time of estimate, and generally unpredictable circumstances during construction (Kaming et al., 1997). These changes after construction has commenced are disruptive to the planned construction process, leading to cost and time overruns (Ireland, 1985). With increasingly lower profitability under the current sluggish economic growth and highly competitive market conditions, the rate of make up is already low and cost overruns caused by design variations and other sources may lead to losses for contractors (Akinci and Fischer, 1998). Therefore, it is crucial that design variations are kept to a minimum in order to reduce construction costs and improve contractor cost performance. A clear and thorough brief, quality contract documentation, and the use of a independent cost manager were perceived as the three most important strategies for reducing design variations by Australian practitioners (Chan and Yeong, 1995) and may be considered effective in other countries.

\section{CONCLUSION}

Construction cost is a major concern to both clients and contractors due to its obvious economic impact on them. This research aimed to identify the factors influencing the construction cost of building projects. Based on a hypothetical six-storey concrete framed building project, a questionnaire survey was conducted in the three leading construction industries, namely Japan, the UK and the US, to collect contractor cost performance data and other relevant information. A construction cost model was developed based on the practices of contractors in the three countries, which identified the paramount factors found to influence contractor cost performance and to highlight possible ways for improvement.

Multiple regression analysis revealed that the percentage of overheads in the unit price, the number of design variations during construction, and the use of prefabrication for the hypothetical project were identified as being closely related to contractor cost performance. Overheads are mainly indirect costs and can be reduced through more effective site management. The use of prefabrication may lead to increased construction cost due to difficulties caused by transportation, poor co-ordination among the participants, and delays to the construction process. Design variations during construction bring more uncertainties and will unavoidably increase the construction cost to both clients and contractors.

While these findings in themselves are not totally surprising, they will be of interest to practitioners and clients alike. Constructers need to reduce their overheads and look at ways of improving their use of prefabrication. Clients and designers need to reduce or at least minimise the number of design variations issued during construction. Findings reported herein, suggested that these will lead to a significant reduction in construction cost.

\section{ACKNOMLEGEMENTS}

The authors acknowledge the support of $\mathrm{Mr}$ Kenichi Matsui of the Public Works Research Institute of the Ministry of Construction of J apan and also numerous project managers in J apan, the UK and the US for their generous cooperation and contributions to this research.

\section{REFERENCES}

Adeli, H. and Wu, M. (1998) Regularization neural network for construction cost estimation. J ournal of Construction Engineering and Management, 124 (1), 18-24.

Ahmed, S.M. and Kangari, R. (1995) Analysis of client-satisfaction factors in construction industry. Journal of Management in Engineering, 11 (2), 36-44.

Akinci, B. and Fischer, M. (1998) Factors affecting contractors' risk of cost overburden. J ournal of Management in Engineering, $14(1), 67-76$. 
Akintoye, A. (1995) J ust-in-Time application and implementation for building material management. Construction Management and Economics, 13, 105-13.

d'Arcy, J . (1995) Cutting costs by 30\%. Contract J ournal, 13 April, 1995, 18-20.

Arditi, D.; Ergin, U. and Gunhan, S. (2000) Factors affecting the use of precast concrete systems. Journal of Architectural Engineering, 6 (3), 79-86.

Ashworth, A. (1996) Pre-contract Studies: Development Economics, Tendering and Estimating. Addison Wesley Longman Limited, Harlow.

Ball, M.; Farshchi, M. and Grilli, M. (2000) Competition and the persistence of profits in the UK construction industry. Construction Management and Economics, 18, 733-45.

Brook, M. (1998) Estimating and Tendering for Construction Work (Second Edition). Butterworth-Heinemann, Oxford.

Chan, A.P.C. and Yeong, C.M. (1995) A comparison of strategies for reducing variations. Construction Management and Economics, 13, 467-73.

Chartered Institute of Building (2000) Directory and list of members - Chartered Institute of Building, Chartered Institute of Building, Stonehart Group, London

Chau, K.W. (1999) On the issue of plan shape complexity: plan shape indices revisited. Construction Management and Economics, 17, 473-82.

CIDA (Construction Industry Development Agency) (1993) Key performance Criteria. Construction Industry Development Agency, Melbourne, Australia.

Davenport, D. (1997) Client satisfaction with construction cost - a comparative study of French and UK performance. Journal of Financial Management of Property and Construction, 2 (3), 77-94.

Dissanayaka, S.M. and Kumaraswamy, M.M. (1999) Comparing contributors to time and cost performance in building projects. Building and Environment, 34 (1), 31-42.

Edkins, A. and Winch, G. (1999) The Performance of the UK Construction Industry: An International Perspective. University College London, London.
Elhag, T.M.S. and Boussabaine, A.H. (1998) An artificial neural system for cost estimation of construction projects. ARCOM Fourteenth Annual Conference 1998, University of Reading, pp. 219-26.

Hair, J r., J .F., Anderson, R.E., Tatham, R.L. and Black, W.C. (1995) Multivariate Data Analysis with Readings, $4^{\text {th }}$ Edition. PrenticeHall International, Inc., Englewood Cliffs, New J ersey.

Hegazy, T. and Ayed, A. (1998) Neural network model for parametric cost estimation of highway projects. Journal of Construction Engineering and Management, 124 (3), 210-18.

Ireland, V. (1985) The role of managerial actions in the cost, time and quality performance of high-rise commercial building projects. Construction Management and Economics, 3, 59-87.

Ishai, E. (1989) Architectural and economic considerations in the design of prefabricated façade components (exterior walls). Construction Management and Economics, 7, 189-202.

J ohnson, R.A. and Wichern, D.W. (1998) Applied Multivariate Statistical Analysis. Prentice-Hall, Inc., Upper Saddle River, New J ersey.

Kaming, P.F.; Olomolaiye, P.O.; Holt, G.D. and Harris, F.C. (1997) Factors influencing construction time and cost overruns on high-rise projects in Indonesia. Construction Management and Economics, 15, 83-94.

Kravis, I.B. (1984) Comparative studies of national incomes and prices. Journal of Economic Literature, 22(March), 1-39.

Low, S.P. and Choong, J.C. (2001) J ust-InTime management of precast concrete components. Journal of Construction Engineering and Management, 127 (6), 494-501.

Low, S.P. and Mok, S.H. (1999) The application of J IT philosophy to construction: a case study in site layout. Construction Management and Economics, 17, 657-68.

Naoum, S. G. and Mustapha, F. H. (1995) Relationship between the building team, procurement methods and project performance. J ournal of Construction Procurement, $1(1), 50-63$. 
Newbold, P. and Bos, T. (1990) Introductory Business Forecasting. South Western Publishing, Cincinnati.

Norusis, M.J . (1995) SPSS: SPSS 6.1 Guide to Data Analysis. Prentice-Hall, Inc., New J ersey.

OECD (2001) Purchasing power parities. Organisation for Economic Co-operation and Development, http://www.oecd.org/std/ppp/ pps.htm (updated on 24/01/2001, accessed on 22/03/2001).

Proverbs, D.G. (1998) $A$ best practice model for high-rise in situ concrete construction based on French, German and UK contractor performance measures. Ph.D. Thesis, University of Wolverhampton.

Reed Business Information (1999) KOMPASS: Products and Services Register 1, 1999/2000 United Kingdom. Reed Business Information, East Frinstead, West Sussex.

Singh, S. (1990) Cost model for reinforced concrete beam and slab structures in buildings. Journal of Construction Engineering and Management, 116 (1), 54-67.

Tah, J.H.M., Thorpe, T. and McCaffer, R. (1994) A survey of indirect cost estimating in practice. Construction Management and Economics, 12, 31-6.

Tam, C.M. and Harris, F. (1996) Model for assessing building contractors' project performance. Engineering, Construction and Architectural Management, 3|3, 187-203.

Wallace, I.N.D. (1995) Hudson's Building and Engineering Contracts (1 $11^{\text {th }}$ Edition). Sweet and Maxwell, London.

Vermande, H. M. and Van Mulligen, P. (1999) Construction costs in The Netherlands in an international context. Construction Management and Economics, 17, 269-83.

Xiao, H., Proverbs, D., Shaw, T. and Holt, G. (2000) A new approach to comparing the performance of contractors internationally. ARCOM Sixteenth Annual Conference 2000, Glasgow Caledonian University, pp. 117-25.

Xiao, H., Proverbs, D., and Holt, G. (2002) A New Paradigm for International Contractor Performance Assessment. J ournal of Construction Research (accepted).
Xiao, H. and Proverbs, D.G. (2002) The performance of contractors in J apan, the UK and the US: a comparative evaluation of construction cost. Construction Management and Economics, (accepted). 